\title{
Gastric Peroral Endoscopic Myotomy
}

\author{
Hyunsoo Chung ${ }^{1}$ and Mouen A Khashab ${ }^{2}$ \\ ${ }^{1}$ Department of Internal Medicine and Liver Research Institute, Seoul National University College of Medicine, Seoul, Korea, ${ }^{2}$ Department of \\ Medicine and Division of Gastroenterology and Hepatology, Johns Hopkins Hospital, Baltimore, MD, USA
}

Gastroparesis (GP) is a syndrome characterized by delayed gastric emptying in the absence of mechanical obstruction of the stomach or proximal small bowel. Currently available dietary and medical therapies are limited and have suboptimal efficacy. Pylorus-directed therapies have showed promising results. Gastric peroral endoscopic myotomy (G-POEM) has been reported for the treatment of GP refractory to standard therapy with promising results. This article reviews the current applications and results of G-POEM for the treatment of refractory GP. Clin Endosc 2018;51:28-32

Key Words: Gastric emptying; Gastroparesis; Pyloromyotomy

\section{INTRODUCTION}

Gastroparesis (GP) is a chronic symptomatic disorder defined by delayed gastric emptying in the absence of mechanical obstruction of the stomach or proximal small bowel. ${ }^{1}$ Unfortunately, current approved treatment options, including dietary modification, pharmacologic therapy, intrapyloric botulinum toxin injection, gastric electrical stimulation, and surgical treatments do not adequately address clinical needs. Recently, peroral endoscopic myotomy (POEM) has been used in the pylorus of the stomach for treatment of GP and is known as gastric POEM (G-POEM), endoscopic pyloromyotomy, or peroral pyloromyotomy. ${ }^{2}$ This article reviews the current applications and results of G-POEM for the treatment of refractory GP.

Received: November 24, 2017 Revised: January 22, 2018

Accepted: January 22, 2018

Correspondence: Mouen A Khashab

Department of Medicine and Division of Gastroenterology and Hepatology, Johns Hopkins Hospital, 1800 Orleans Street, Suite 7125 B, Baltimore, MD 21205, USA

Tel: +1-443-287-1960, Fax: +1-443-683-8335, E-mail: mkhasha1@jhmi.edu

(c) This is an Open Access article distributed under the terms of the Creative Commons Attribution Non-Commercial License (http://creativecommons.org/ licenses/by-nc/3.0) which permits unrestricted non-commercial use, distribution, and reproduction in any medium, provided the original work is properly cited.

\section{GASTROPARESIS}

GP is a disorder defined by delayed gastric emptying in the absence of mechanical obstruction of the stomach or proximal small bowel. The range of symptoms includes nausea, retching, vomiting, postprandial fullness, epigastric discomfort and pain, loss of appetite, bloating, and abdominal distention. Approximately $90 \%$ of patients with GP have either diabetic, postsurgical, or idiopathic GP. ${ }^{3}$ Gastric emptying is mediated by the vagus nerve, smooth muscle cells, interstitial cells of Cajal, and enteric neurons that regulate fundic accommodation, antral contraction, and pyloric relaxation. ${ }^{4}$ The pathophysiology of GP has not been fully elucidated but abnormalities in these elements seem to be involved. Histologic studies show defects in the morphology of enteric neurons, smooth muscle cells, and interstitial cells of Cajal, and increased concentrations of inflammatory cells in gastric tissue. ${ }^{5,6}$ Fundic hypocontractility, antral hypomotility, pylorospasm, antropyloroduodenal incoordination, gastric arrhythmia, and autonomic neuropathy all contribute to delays in gastric emptying and symptom expression. ${ }^{7}$ Post-vagotomy GP occurs in $15 \%-50 \%$ of patients following esophagectomy with gastric interposition, and results in aspiration pneumonia, persistent nausea, intolerance of oral intake, weight loss, and poor quality of life (QoL). ${ }^{8}$ This can contribute to significant morbidity and mortality in these patients. The efficacy of pyloric drainage procedures to prevent 
post-vagotomy GP remains unclear. Due to the complexity and poor understanding of the pathophysiology of GP, all current therapy is palliative as well as empirical.

\section{SUBMUCOSAL ENDOSCOPY, POEM, AND G-POEM}

The submucosa has not attracted endoscopists' attention. However, in the era of natural orifice transluminal endoscopic surgery (NOTES), the submucosa became important because a fundamental step in NOTES is secure closure of intentional perforation of the entry organ. Sumiyama et al. reported submucosal endoscopy with mucosal flap methods for the closure of the entry organ in 2007. ${ }^{9}$ Following this report, Pasricha et al. introduced the concept of POEM in animal experiments and Inoue et al. reported the first clinical data of POEM for achalasia. ${ }^{10,11}$ Meanwhile, Park et al. replicated Heineke-Mikulicz pyloroplasty endoscopically using a needle knife and T-tags and Kawai et al. performed endoscopic pyloromyotomy in a porcine model. ${ }^{1213}$ In 2013, Khashab et al. described the first G-POEM in a human case of refractory diabetic GP and Chung et al. first reported G-POEM in a patient with refractory postoperative $\mathrm{GP}^{14,15}$ Since then, there have been several reports in the literature suggesting that the G-POEM technique is both safe and effective and can have an impact on both symptoms and gastric emptying. ${ }^{2,16}$

\section{G-POEM}

\section{Technique}

G-POEM and POEM techniques are the same; therefore, the principles of G-POEM are similar to those of POEM, consisting of submucosal injection, mucosal incision, submucosal tunneling, myotomy, and closure of mucosal entry. ${ }^{10,17}$ The procedure can be performed under general anesthesia or conscious sedation. Carbon dioxide $\left(\mathrm{CO}_{2}\right)$ gas insufflation is necessary to minimize the risk of tension pneumoperitoneum, and may require percutaneous or surgical decompression because $\mathrm{CO}_{2}$ is absorbed from the gastrointestinal tract approximately 160 times faster than nitrogen, the major component of room air. ${ }^{18}$ During the procedure, the patient can be in either lateral decubitus or supine position.

Before starting mucosal injection, food residue in the stomach should be cleaned by irrigation, suction, or lavage. A conventional gastroscope can be used, but a water-jet-integrated gastroscope is preferred to obtain a clearer view. Use of a transparent cap is also recommended to enhance image stabilization. After proper preparation, a submucosal injection of 3-5 cc of hypertonic saline mixed with methylene blue or indigo carmine is made at the greater curvature or anterior wall of the antrum, about $5 \mathrm{~cm}$ from the pyloric ring.

As with POEM, creation of a 1.5 to $2 \mathrm{~cm}$ mucosal entry is performed at the site of the initial submucosal bleb using an endoscopic needle knife or DualKnife. A longitudinal incision
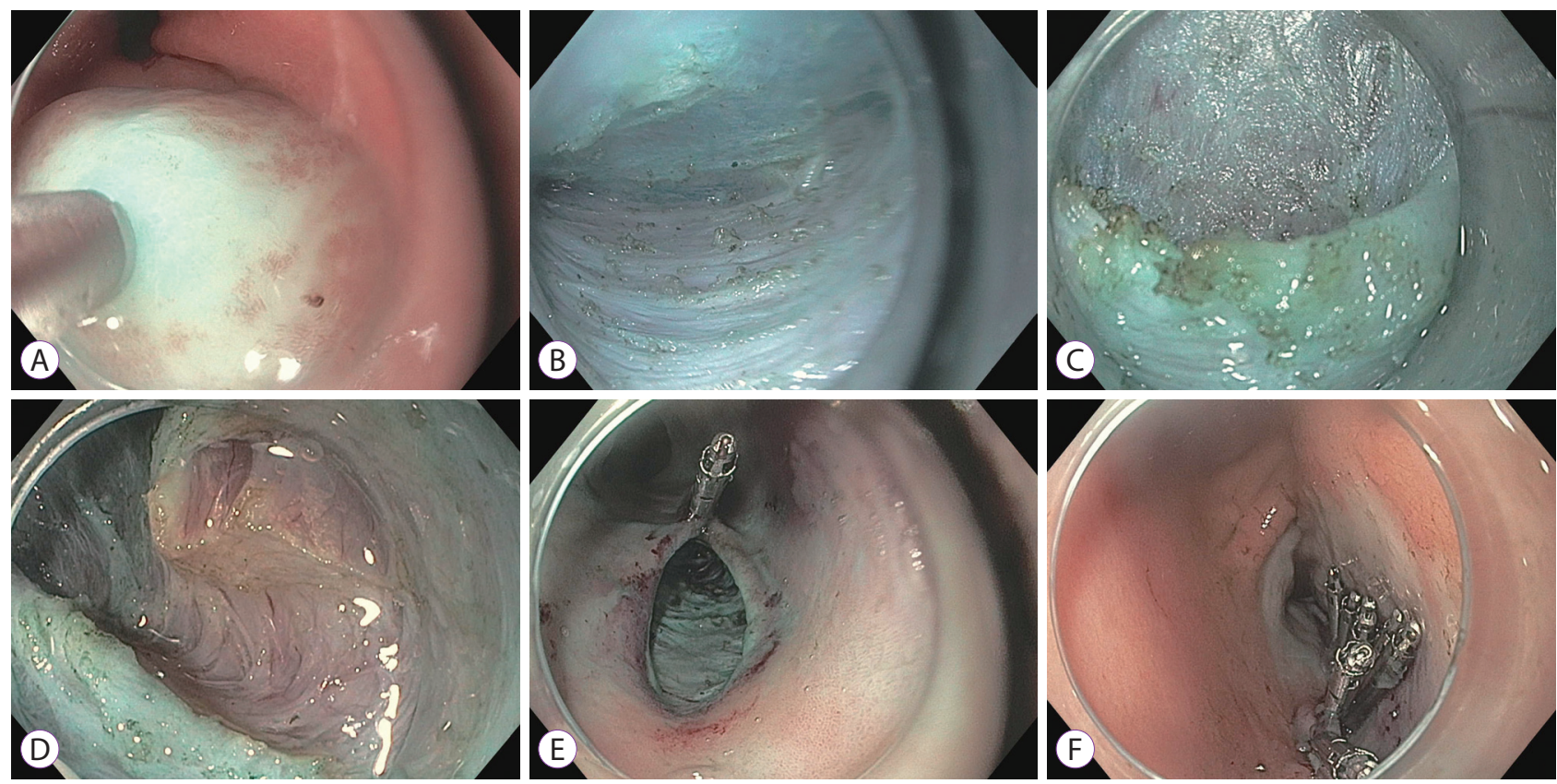

Fig. 1. Gastric peroral endoscopic myotomy performed in a patient with idiopathic gastroparesis. (A) Submucosal bleb is created $5 \mathrm{~cm}$ proximal to the pylorus at the 5 o'clock position along the greater curve. (B) Submucosal tunnel is created until the pyloric ring (C) is reached. (D) Pyloromyotomy is performed using an insulated-tip knife to avoid injury to the adjacent duodenal wall. (E, F) Closure of the mucosal entry site is accomplished using through-the-scope clips. 
is preferred because closure with clips is easier; however, a transverse approach is also used. A blended-current electrosurgical unit setting is preferred (e.g., VIO 300D [ERBE, Tübingen, Germany] EndoCut I 2:3:3 or 2:3:2, or EndoCut Q 3:1:1). Following incision, the scope is inserted gently into the submucosal layer. This initial entry is not easy and should not be rushed, to prevent early bleeding or muscle injury, which impede subsequent steps. After the scope is inserted, submucosal tunneling is made towards the pylorus using the same blended current or spray coagulation (effect 2, $50 \mathrm{~W}$ ). Injection of sufficient solution is required for safe and fast tunneling and avoidance of mucosa-side injury, as with POEM. Unlike tunneling in the esophagus, identifying the correct direction of the pylorus is not easy, and several attempts at tunnel exit and reentry may be needed. Small vessels can be managed using spray coagulation; however, large blood vessels need to be coagulated preemptively with a coagulation forceps (Coagrasper, FD-410LR; Olympus, Tokyo, Japan) and a soft coagulation setting (Soft Coag 30-50 W). The sphincter can be identified as a whitish round muscular bundle when the scope reaches the pylorus. The length of myotomy ranges between 1.5 and $3 \mathrm{~cm}$ in most reports. Considering that the thickness of the pyloric ring is generally less than $1 \mathrm{~cm}$, an additional 1- to $2-\mathrm{cm}$ myotomy of the gastric antrum is made. The direction of myotomy can be either anterograde or retrograde. Cutting only the inner circular muscle of the pylorus and gastric antrum is recommended, without performing full-thickness myotomy. As with POEM, the entry site and mucosal incision is closed with either clips or endoscopic sutures (Fig. 1). ${ }^{17}$

\section{Clinical outcomes}

Clinical outcomes have been reported in about 130 patients in 5 studies. ${ }^{2,16,19-21}$ All studies were retrospective, and there has been no prospective study or randomized controlled trial (Table 1).

Shlomovitz et al. reported the first case series in 7 patients with GP (5 idiopathic and 2 postoperative). ${ }^{2}$ All procedures were technically successful without immediate procedural complications. A few perioperative complications were reported, including 1 case of upper gastrointestinal bleeding 2 weeks postoperatively, 1 case of swallowing difficulty delaying discharge by 1 day, and case of 1 hospital-acquired pneumonia. Six of the 7 patients experienced significant symptomatic improvement. Three-month follow-up nuclear medicine solid-phase gastric-emptying scan (GES), was available for 5 of the 7 patients. Normal gastric emptying at $4 \mathrm{~h}$ was noted in 4 of the 5 patients (80\%). Khashab et al. reported the results from the first multicenter study. ${ }^{20}$

A total of 30 patients with refractory GP (11 diabetic, 12 postsurgical, 7 idiopathic) underwent G-POEM without technical

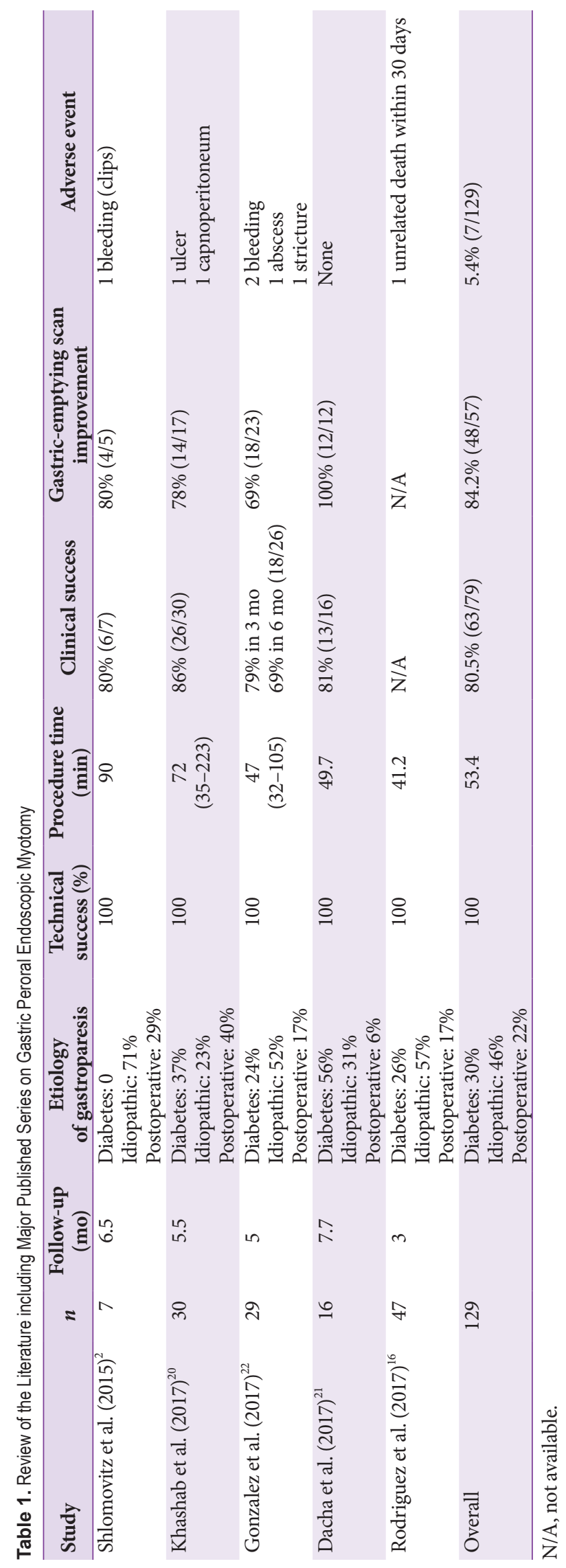


failure, and the technical details included a mean procedure time of $72 \mathrm{~min}$ and a mean myotomy length of $2.3 \mathrm{~cm}$. Two adverse events occurred in 2 (6.7\%) patients, including 1 case of capnoperitoneum and 1 prepyloric ulcer. Clinical response rate was $86 \%$ during a median follow-up of 5.5 months. Four patients ( 2 diabetic, 1 postsurgical, 1 idiopathic cause) did not respond to G-POEM. Among 17 of 30 patients, there was improvement in gastric emptying time in $82.4 \%$ (14/17), including normalization in $47 \%$ and partial improvement in $35 \%$. Gonzalez et al. also reported favorable mid-term efficacy in 29 GP patients. ${ }^{22}$ The GP Cardinal Symptom Index (GCSI) at 3 and 6 months and the change in GES were outcomes. The technical success rate was 100\% (average $47 \mathrm{~min}$ ) with minor complications (1 bleeding and 1 abscess). The clinical success rate was $79 \%$ at 3 months and $69 \%$ at 6 months, and the GES normalized in $70 \%$ of cases. Factors associated with poor response were investigated and diabetes and female sex were significantly associated with risk of failure in univariate analysis. Dacha et al. reported clinical outcomes including QoL assessment in 16 patients. ${ }^{21}$ G-POEM was technically successful in all cases. ${ }^{21}$ They reported $81 \%$ improvement in the mean GCSI and QoL after G-POEM without adverse events during mean a follow-up of 7.7 months. Improvement in mean 4-h gastric retention on GES was sustained for 12 months. Rodriguez et al. reported the outcome in 47 patients (57.4\% idiopathic, $25.6 \%$ diabetic, $17 \%$ postoperative). ${ }^{16}$ The average percentage of retained food at $4 \mathrm{~h}$ was improved from $37 \%$ to $20 \%$ and GCSI was also improved significantly. Overall, G-POEM can be safely performed in experienced hands and the mid-term clinical response ranges from $70 \%-90 \%$.

\section{FUTURE PERSPECTIVES}

Even though several studies reported favorable short- and mid-term clinical outcomes and significant improvement in scintigraphic findings, the level of evidence is still inadequate. A prospective, randomized controlled trial is needed for comparison with conventional treatment modalities. Considering the complex pathophysiology of GP and the outcomes of previous studies, there seem to be different subsets of patients. Studies to elucidate factors associated with favorable or poor clinical response to G-POEM are necessary. G-POEM may be helpful in patients with pylorospasm and/or antropyloroduodenal incoordination because it directly affects the pyloric ring and distal antrum. Several methods are used to assess pyloric function. Pyloric manometry is considered the standard but is limited by space between sensors, catheter migration, and patient discomfort. Wireless motility capsule and impedance planimetry are both emerging technologies that appear quite promising. However, data on healthy subjects and patients are still lacking. ${ }^{23}$ Pyloric dysfunction is known to be associated with more severe early satiety and postprandial fullness in patients with GP, and pylorospasm was observed in about $60 \%$ of patients with diabetic GP. ${ }^{24,25}$ Therefore, risk factor assessment and evaluation of pyloric function seems to be important for achieving the best results with G-POEM.

\section{CONCLUSIONS}

G-POEM is a safe, effective, and minimally invasive treatment for refractory GP, with promising short- and mid-term efficacy. Prospective comparative studies with long-term follow-up are necessary to confirm the results of previous studies. In addition, studies on optimal patient selection and factors associated with treatment response should be performed.

Conflicts of Interest

The authors have no financial conflicts of interest.

\section{REFERENCES}

1. Parkman HP, Hasler WL, Fisher RS; American Gastroenterological Association. American gastroenterological association technical review on the diagnosis and treatment of gastroparesis. Gastroenterology 2004;127:1592-1622.

2. Shlomovitz E, Pescarus R, Cassera MA, et al. Early human experience with per-oral endoscopic pyloromyotomy (POP). Surg Endosc 2015;29:543-551.

3. Soykan I, Lin Z, Sarosiek I, McCallum RW. Gastric myoelectrical activity, gastric emptying, and correlations with symptoms and fasting blood glucose levels in diabetic patients. Am J Med Sci 1999;317:226-231.

4. Camilleri M, Parkman HP, Shafi MA, Abell TL, Gerson L; American College of Gastroenterology. Clinical guideline: management of gastroparesis. Am J Gastroenterol 2013;108:18-37; quiz 38.

5. Pasricha PJ, Parkman HP. Gastroparesis: definitions and diagnosis. Gastroenterol Clin North Am 2015;44:1-7.

6. Grover M, Farrugia G, Lurken MS, et al. Cellular changes in diabetic and idiopathic gastroparesis. Gastroenterology 2011;140:1575-1585.e8.

7. Pasricha PJ. Future directions in the treatment of gastroparesis. Gastroenterol Clin North Am 2015;44:185-189.

8. Lee HS, Kim MS, Lee JM, Kim SK, Kang KW, Zo JI. Intrathoracic gastric emptying of solid food after esophagectomy for esophageal cancer. Ann Thorac Surg 2005;80:443-447.

9. Sumiyama K, Gostout CJ, Rajan E, Bakken TA, Knipschield MA, Marler RJ. Submucosal endoscopy with mucosal flap safety valve. Gastrointest Endosc 2007;65:688-694.

10. Inoue $\mathrm{H}$, Minami $\mathrm{H}$, Kobayashi $\mathrm{Y}$, et al. Peroral endoscopic myotomy (POEM) for esophageal achalasia. Endoscopy 2010;42:265-271.

11. Pasricha PJ, Hawari R, Ahmed I, et al. Submucosal endoscopic esophageal myotomy: a novel experimental approach for the treatment of achalasia. Endoscopy 2007;39:761-764.

12. Kawai M, Peretta S, Burckhardt O, Dallemagne B, Marescaux J, Tanigawa N. Endoscopic pyloromyotomy: a new concept of minimally invasive surgery for pyloric stenosis. Endoscopy 2012;44:169-173.

13. Park PO, Bergström M, Ikeda K, et al. Endoscopic pyloroplasty with full-thickness transgastric and transduodenal myotomy with sutured 
closure. Gastrointest Endosc 2007;66:116-120.

14. Khashab MA, Stein E, Clarke JO, et al. Gastric peroral endoscopic myotomy for refractory gastroparesis: first human endoscopic pyloromyotomy (with video). Gastrointest Endosc 2013;78:764-768.

15. Chung H, Dallemagne B, Perretta S, et al. Endoscopic pyloromyotomy for postesophagectomy gastric outlet obstruction. Endoscopy 2014;46 Suppl 1 UCTN:E345-E346.

16. Rodriguez JH, Haskins IN, Strong AT, et al. Per oral endoscopic pyloromyotomy for refractory gastroparesis: initial results from a single institution. Surg Endosc 2017;31:5381-5388.

17. Benias PC, Khashab MA. Gastric peroral endoscopic pyloromyotomy therapy for refractory gastroparesis. Curr Treat Options Gastroenterol 2017;15:637-647.

18. ASGE Technology Committee, Lo SK, Fujii-Lau LL, et al. The use of carbon dioxide in gastrointestinal endoscopy. Gastrointest Endosc 2016;83:857865.

19. Hernández-Mondragón OV, Solórzano-Pineda OM, Blancas-Valencia JM, González-Martínez MA, Villanueva-Pérez RM. Gastric per-oral endoscopic pyloromyotomy in the treatment of refractory gastroparesis: report on the first case performed in Mexico. Rev Gastroenterol Mex 2017
Jul 3 [Epub]. https://doi.org/10.1016/j.rgmx.2017.03.006.

20. Khashab MA, Ngamruengphong S, Carr-Locke D, et al. Gastric per-oral endoscopic myotomy for refractory gastroparesis: results from the first multicenter study on endoscopic pyloromyotomy (with video). Gastrointest Endosc 2017;85:123-128.

21. Dacha S, Mekaroonkamol P, Li L, et al. Outcomes and quality-of-life assessment after gastric per-oral endoscopic pyloromyotomy (with video). Gastrointest Endosc 2017;86:282-289.

22. Gonzalez JM, Benezech A, Vitton V, Barthet M. G-POEM with antro-pyloromyotomy for the treatment of refractory gastroparesis: mid-term follow-up and factors predicting outcome. Aliment Pharmacol Ther 2017;46:364-370.

23. Clarke JO, Snape WJ Jr. Pyloric sphincter therapy: botulinum toxin, stents, and pyloromyotomy. Gastroenterol Clin North Am 2015;44:127-136.

24. Malik Z, Sankineni A, Parkman HP. Assessing pyloric sphincter pathophysiology using EndoFLIP in patients with gastroparesis. Neurogastroenterol Motil 2015;27:524-531.

25. Mearin F, Camilleri M, Malagelada JR. Pyloric dysfunction in diabetics with recurrent nausea and vomiting. Gastroenterology 1986;90:1919-1925. 